\title{
Rape Victim Blaming as System Justification: The Role of Gender and Activation of Complementary Stereotypes
}

\author{
Tomas Ståhl • Daniel Eek • Ali Kazemi
}

Published online: 10 November 2010

(C) The Author(s) 2010. This article is published with open access at Springerlink.com

\begin{abstract}
This research examined reactions towards female rape victims from a system justification perspective. Study 1 demonstrated that gender-related system justification motivation (Modern Sexism) predicted the propensity to blame a female rape victim among men, but not among women. Modern sexism predicted rape victim blaming among men even when statistically controlling for a general antipathy towards women, and the results were unaffected by social desirability concerns. Consistent with previous study on system justification theory, we demonstrated in Study 2 that system justification motivation can predict victim blaming also among women, provided that complementary stereotypes about women have been activated. By contrast, system justification motivation predicted men's propensity to blame a rape victim irrespective of whether complementary stereotypes about women had been experimentally activated.
\end{abstract}

Keywords Victim blaming - System justification · Modern sexism ·

Complementary stereotypes · Rape myths

Previous research has demonstrated that rape victims are vulnerable to so-called secondary victimization (Campbell et al., 1999). This predicament implies that rape

T. Ståhl (ه)

Section for Social and Organizational Psychology, Institute for Psychological Research, Leiden

University, P.O. Box 9555, 2300 RB Leiden, The Netherlands

e-mail: tstahl@fsw.leidenuniv.nl

D. Eek

Göteborg University, Göteborg, Sweden

A. Kazemi

University of Skövde, Skövde, Sweden 
victims not only have to suffer from the sexual transgression itself, but also from people in their surroundings who tend to see them as partially responsible for what happened to them (Pollard, 1992). Not surprisingly, such secondary victimization often has negative consequences for the well-being of the victim (Campbell et al., 1999; Katz \& Burt, 1988). Moreover, the possibility of being viewed as responsible for being raped most likely contributes to rape victims' reluctance to report transgressions to proper authorities. For example, the Swedish National Council for Crime Prevention has estimated that only about $20 \%$ of actual rape incidents in Sweden are reported to the police (BRA, 2005). For several reasons, then, it is important to identify the conditions under which people are likely to blame victims of rape and to increase our understanding of the psychological processes accounting for such responses.

Social psychologists have examined the propensity to blame female victims of rape ever since the 1970s, and the phenomenon is by now well established (for overviews, see, Lonsway \& Fitzgerald, 1994; Pollard, 1992). Furthermore, there is ample evidence that men generally blame female rape victims more than women do (for a review, see Pollard, 1992). In general, the propensity to blame female rape victims has been attributed to various mythological beliefs about rape and rape victims that are predominantly accepted by men (Burt, 1980; Lonsway \& Fitzgerald, 1994). In this article we argue that, although research on rape myth acceptance has provided a powerful tool to predict the propensity to blame female rape victims, somewhat less is known about the presumed motivational underpinnings of rape victim blaming (cf. Lonsway \& Fitzgerald, 1995). Thus far, most research suggests that rape myth acceptance and rape victim blaming is driven by a general hostility towards women (Lonsway \& Fitzgerald, 1995, but see Abrams, Viki, Masser, \& Bohner, 2003). In this research, we argue that there is another motive that contributes to rape victim blaming. Based on system justification theory (Jost \& Banaji, 1994; Jost, Banaji, \& Nosek, 2004), we argue that attributing blame to a rape victim can be understood as a response to a threat to the status quo. More specifically, we argue that innocent rape victims threaten system justifying beliefs that contemporary society offers "a level playing field" for men and women. As a consequence, we expect that system justification motivation should contribute to negative reactions towards rape victims beyond what can be explained by a general hostility towards women. Before we outline our theoretical reasoning in more detail and delineate the specifics of this research we shall first review previous research on rape myth acceptance.

\section{Rape Myth Acceptance}

Rape myths are "attitudes and beliefs that are generally false but are widely and persistently held, and that serve to deny and justify male sexual aggression against women" (Lonsway \& Fitzgerald, 1994, p. 134). An illustration of such a mythological belief is the idea that "women routinely lie about being raped." This belief is widely held, although the available evidence shows that women are highly reluctant to report that they have been raped even when it is the truth (e.g., BRA, 2005). 
While the invalidity of beliefs about rape is interesting in its own right, we are presently more interested in the effects such beliefs have on reactions towards specific victims of rape, and the motivational underpinnings that explain these responses. Notably, a substantial number of studies have demonstrated that acceptance of rape myths predicts how people perceive descriptions of rape cases, as well as perceptions of the victims and perpetrators of rape. People high on rape myth acceptance frequently fail to acknowledge that descriptions fitting the legal definition of rape are in fact examples of rape (e.g., Fischer, 1986; Norris \& Cubbins, 1992). Furthermore, studies have generally found that people high (vs. low) on rape myth acceptance assign less responsibility and blame to perpetrators (Check \& Malamuth, 1985; Quackenbush, 1989), and more responsibility and blame to victims of rape (e.g., Blumberg \& Lester, 1991; Check \& Malamuth, 1985; Jenkins \& Dambrot, 1987; Linz, Donnerstein, \& Adams, 1989; Linz, Donnerstein, \& Penrod, 1988; Muehlenhard \& MacNaughton, 1988). In short, rape myth acceptance is a reliable predictor of various reactions to rape incidents. We now turn to the question of what underlying motives may ultimately explain the persistence of rape myths and their influence on reactions to rape victims.

\section{Rape Victim Blaming as System Justification}

As explicitly stated in the definition of rape myths above, it has generally been assumed that rape myths serve to justify male sexual aggression (Burt, 1980). Consistent with this idea, Lonsway and Fitzgerald (1995) demonstrated that previously proposed antecedents of rape myth acceptance (e.g., gender role attitudes, adversarial sexual beliefs, acceptance of interpersonal violence, Burt, 1980) can be accounted for by a more general hostility towards women. Notably, however, hostile attitudes towards women appear to be a better predictor of rape myth acceptance among men than among women (Lonsway \& Fitzgerald, 1995). This finding suggests that rape myths may serve different functions for men and women. Indeed, it has been suggested that rape myths may serve to reduce women's feelings of personal vulnerability by ensuring that only particular women are raped (Bohner, Siebler, \& Raaijmakers, 1999; Lonsway \& Fitzgerald, 1994, cf. Correia, Vala, \& Aguiar, 2007).

Aside from justifying male sexual aggression and reducing women's feelings of personal vulnerability, we argue that rape myths and rape victim blaming also serve the more general function of justifying the status quo. System justification theory (SJT, Jost \& Banaji, 1994; Jost et al., 2004) posits that, apart from motives to protect personal and group interests, "people are motivated to justify and rationalize the way things are, so that existing social, economic, and political arrangements tend to be perceived as fair and legitimate" (Jost \& Hunyady, 2005, p. 260). While the system justification motive is conceived of as a general motive, its strength varies across individuals and situations. For example, a dispositional need for order, a need for closure, as well as a lack of openness to experience have been linked to system justification motivation (Jost, Glaser, Kruglanski, \& Sulloway, 2003; Jost \& Hunyady, 2005). Several situational antecedents of system justification motivation 
have also been identified, such as direct threats to the system and salient existential concerns (Jost, Blount, Pfeffer, \& Hunyady, 2003; Landau et al., 2004).

According to SJT, there are a host of different ideologies in our society that can be (and are) used to protect the status quo. For example, the protestant work ethic (Jost \& Hunyady, 2002), meritocratic ideology (Jost, Pelham, Sheldon, \& Sullivan, 2003), power distance (Jost et al., 2003), the belief in a just world (Jost \& Burgess, 2000), and opposition to equality (Jost \& Thompson, 2000) have all been found to serve system justifying functions. The notion that these ideologies all serve a general function to legitimize current societal arrangements is further corroborated by the fact that they are all positively correlated (Jost \& Hunyady, 2005). In research on system justification, variation in any of these beliefs is, therefore, generally viewed as differences in system justification motivation.

But how can system justification motivation contribute to our understanding of rape myth acceptance and rape victim blaming? A central tenet of SJT is that threats to the system and to system justifying ideologies trigger attempts to justify the system (Jost et al., 2003). We propose here that innocent victims of rape should constitute a threat to system justifying conceptions of the world as a fair place in general (Abrams et al., 2003; Lerner, 1980), and to conceptions that contemporary society offers a "level playing field" for men and women in particular. Exposure to innocent rape victims should, therefore, trigger attempts to justify the status quo, particularly among people who have strong system justification motives. We further posit that a common strategy to do this is by attributing blame to the victim of rape (cf. Abrams et al., 2003).

Some relevant albeit indirect support for our line of reasoning was reported by Hafer (2000). She used an emotional Stroop task to examine whether innocent victims threaten the belief in a just world (BJW, Lerner, 1980)—an ideology that serves to protect the status quo (Jost \& Burgess, 2000). Emotional Stroop tasks are used to measure attentional biases, and it has frequently been demonstrated that people display an attentional bias towards stimuli related to their current concerns (Mogg, Mathews, Bird, \& Macgregor-Morris, 1990; Williams, Mathews, \& MacLeod, 1996). Hafer reasoned that, to the extent that innocent victims threaten the BJW, people should demonstrate an attentional bias towards justice-related stimuli when exposed to an innocent victim. Indeed, after being exposed to a story about a male victim of physical assault, and where the perpetrators got away, people displayed an attentional bias towards justice-related words (vs. control). Importantly, and consistent with the notion that victim blaming serves to reduce BJWthreat, subsequent victim blaming was predicted by the threat to BJW. That is, the more attentional bias people displayed towards justice-related words, the more blame they assigned to the victim.

We propose that similar system justification processes should operate in response to victims of rape. Therefore, we expect that individual differences in gender-related system justification motives should predict rape victim blaming. Specifically, victim blaming should be higher among individuals who tend to deny continued discrimination against women, and who are opposed to women's demands and to societal changes aimed to advance the position of women. However, because of women's disadvantaged position in society, protecting the status quo actually works 
against the interests of their group. By contrast, because of men's advantaged position in society, their system justification motivation goes hand in hand with motivation to protect group-based interests (Sidanius \& Pratto, 1999). As a result, gender-related system justification should be pervasive among men, whereas less consistent responses should be expected among women. Consistent with this line of reasoning, research has shown that system justification motivation induces ambivalent feelings towards victims of gender discrimination among women, whereas system justification motivation reduces ambivalence towards victims of gender discrimination among men (Jost \& Burgess, 2000). Based on this analysis, we predict that men (vs. women) should display a stronger positive relationship between gender-related system justification motivation on the one hand, and rape victim blaming on the other (Hypothesis 1 ).

At the same time, however, there is evidence that people do defend the status quo even at the expense of personal as well as group interests (Jost et al., 2004). According to SJT, system justifying responses among the disadvantaged are facilitated by the operation of complementary stereotypes (Jost \& Kay, 2005; Kay \& Jost, 2003). Complementary stereotypes are stereotypes that highlight positive as well as negative attributes of advantaged and disadvantaged groups in society. For example, complementary stereotypes about women suggest that they are communal but not agentic, whereas complementary stereotypes about men suggest that they are agentic but not communal. According to SJT, the complementary nature of these stereotypes facilitates system justification among the disadvantaged by reminding them that their disadvantage in certain domains is balanced by their advantaged position in other domains. As a result, complementary stereotypes may reduce the salience of group-based justice concerns among the disadvantaged and thereby increase their support for the status quo. Jost and Kay (2005) provided support for this line of reasoning. They found that, while women generally exhibited weaker support for the status quo than men, system justification was equally high among women as among men when complementary stereotypes had been activated. Comparable increases in general system justification have also been obtained by priming other complementary stereotypes such as "poor but happy", "rich but miserable", and "lazy but social" (Kay \& Jost, 2003; Kay, Jost, \& Young, 2005). Kay and Jost (2003) also provided evidence for the underlying process. Specifically, they demonstrated that exposure to complementary stereotypes prevents concerns about justice from being activated. Whereas exposure to noncomplementary stereotypes led to faster responses to justice-related (vs. neutral) words in a Lexical Decision Task, this was not the case when exposed to complementary stereotypes.

Based on this line of reasoning, we propose that the activation of complementary stereotypes about women should facilitate women's system justifying responses towards victims of rape by reducing the salience of group-based justice concerns. As a consequence, we predict that the relationship between system justification motivation and victim blaming should be stronger among women when complementary stereotypes have been activated (vs. control). By contrast, system justification motivation should have an equally strong positive relationship with rape victim blaming among men irrespective of whether complementary stereotypes have been activated or not (Hypothesis 2). 


\section{Overview of Studies}

In this article we extend previous study on reactions to rape victims by directly examining in two studies how system justification motivation contributes to the attribution of blame to a rape victim. In both studies we assessed individual differences in system justification motivation. As we were interested in genderrelated system justification, we opted for a scale designed to measure denial of continuing gender discrimination, antagonism towards women's demands, and resentment towards special favors for women-the Modern Sexism Scale (MS, Swim, Aikin, Hall, \& Hunter, 1995).

In Study 1 we examined the relationship between gender-related system justification (MS) and attributions of blame to a female victim of rape. The aim was to demonstrate that gender-related system justification motivation primarily predicts rape victim blaming among men (vs. women). In addition, we attempted to rule out the alternative interpretation that the influence of system justification motivation (MS) on victim blaming is attributable to a general antipathy towards women (cf. Lonsway \& Fitzgerald, 1995). Finally, because of the sensitive nature of this research topic, we also investigated whether our results where contaminated by social desirability concerns.

In order to convincingly demonstrate that system justification motives contribute to rape victim blaming, it is important to show such responses also among the disadvantaged (i.e., among women). When men blame a female rape victim, they may ultimately not be driven by motivation to protect the status quo per se, but by motivation to protect a status quo in which they belong to the advantaged group (Sidanius \& Pratto, 1999). To the extent that general system justification processes contribute to rape victim blaming, however, it should be possible to find evidence of this also among women. Consistent with previous study on SJT (e.g., Jost \& Kay, 2005), we, therefore, examined in Study 2 whether priming complementary stereotypes about women could trigger rape victim blaming among women as a function of their system justifying motives. In this respect, Study 2 provides a more conservative test of the system justification account of rape victim blaming. Moreover, it also contributes to the understanding of why, although more common among men, rape victim blaming also occurs among women.

\section{Study 1}

In Study 1 we examine whether gender-related system justification motivation primarily contributes to rape victim blaming among men (vs. women). We tested this hypothesis by assessing individual differences in modern sexist attitudes. In order to rule out that our findings are attributable to a general antipathy towards women we also measured classical sexism (Ekehammar, Akrami, \& Araya, 2000). After that, participants were exposed to a fictitious rape scenario and answered questions concerning the victim's blameworthiness. Although reactions to a fictive scenario may frequently deviate from reactions to real-life events, we believe this is less of an issue for research on rape victim blaming. People frequently do not form 
judgments about rape incidents based on interactions with the victims themselves. Rather, they more often hear about these incidents in the media or from their peers. As a result, reading and reacting to a scenario describing a rape is rather similar to many of the "real-life" experiences we ultimately aim to explain (Abrams et al., 2003). In addition, it is for obvious reasons difficult to examine "real" responses to victims under controlled circumstances. For these reasons, we believe that scenario studies are suitable to examine the psychological processes involved in rape victim blaming. After the scenario study, we also assessed individual differences in social desirability concerns (Crowne \& Marlowe, 1960) to investigate whether our measures were contaminated by self-presentation biases.

\section{Method}

\section{Participants}

Undergraduate students ( $N=36,18$ men, 18 women) between 19 and 38 ( $M=23$, $S D=3.53$ ) years of age at University of Skövde volunteered to fill out a questionnaire. Participation took approximately $30 \mathrm{~min}$ and all participants received a movie-ticket in return for their participation.

\section{Materials and Procedure}

Materials were handed out during regular classes. A male experimenter monitored participants and informed them that their participation was guaranteed to be anonymous. Participants were informed that the materials contained a set of different studies. It was announced that questions should be filled out in the order presented. The "first study" was introduced as a short questionnaire on relations between men and women. This part of the questionnaire contained a measure of gender-related system justification motivation and a measure of antipathy towards women. To measure gender-related system justification motivation, we used a validated Swedish version of the Modern Sexism Scale (Ekehammar et al., 2000; Swim et al., 1995). The scale contains 8 items measured on a 6-point scale ( 1 = Disagree completely; $6=$ Agree completely). Examples of items from this scale are: "Discrimination against women is no longer a problem in Sweden" and "The women's movement serves no purpose and should be abolished." After reverse-coding scores on two items so that higher scores consistently indicated higher endorsement of modern sexist attitudes, scores on all items were averaged to create a reliable MS scale $(\alpha=.83)$. To assess antipathy towards women we used a validated 7-item measure of classical sexism (CS, Ekehammar et al., 2000). Examples of items from this scale are "Women are generally not very talented," and "The work of men is more important than the work of women." After reversecoding scores on three items so that higher scores consistently indicated higher endorsement of classical sexist attitudes, scores on all items were averaged to create a reliable CS scale $(\alpha=.62)$.

This was followed by an ostensibly unrelated study. Consistent with previous study on victim blaming (Abrams et al., 2003; Pollard, 1992), participants were 
asked to read a scenario and imagine that it actually happened. In the scenario a (fictitious) rape was described (see appendix). The scenario described a young woman (Sara) attending a party with some friends. At the party she spent time dancing with a man (Mikael) she had previously met on occasion, but that she did not know very well. Later in the evening, she was feeling tired and a bit dizzy from drinking alcohol. Mikael led her to a more quiet room to rest. On a bed in this room he eventually raped her.

Several measures were taken to facilitate perceptions of victim responsibility. First, the victim's clothing was described as relatively sexy (she wore a tight top and a short skirt). Second, acquaintance between the victim and perpetrator was stressed (Abrams et al., 2003). Third, factors that may accentuate perceptions of the victim's recklessness were introduced. It was stated in the scenario that Sara had been drinking to the extent that she was a bit drowsy and dizzy, and it was made clear that she voluntarily followed Mikael into another room to rest. Previous research suggests that all these factors may facilitate victim blaming by affecting the perceived respectability of the victim as well as the perceived recklessness of the victim's behavior (Pollard, 1992).

After reading the scenario, participants were asked to answer some questions about the scenario. Victim blaming was measured on a 6 -point scale $(1=$ to a very low extent; 6 = to a very high extent), using three items, "To what extent did Sara do anything wrong?", "To what extent can Sara be blamed for her actions?", and "To what extent could Sara influence the situation?" $(\alpha=.75)$. After completing these questions, all participants participated in an unrelated scenario study. ${ }^{1}$ In order to ensure that our results were not contaminated by self-presentational biases (e.g., Gerger, Kley, Bohner, \& Siegler, 2007), participants finally filled out a short version of the Marlowe-Crowne Social Desirability Scale (Crowne \& Marlowe, 1960). The short version of this scale consisted of 8 items, e.g., "I am always willing to admit when I have made a mistake," and "Irrespective of who I am talking to, I am always a good listener." All items were answered on a 7-point scale $(1=I$ do not agree at all, $7=$ I agree completely). After reverse coding two items so that higher scores on all items indicated higher social desirability concerns, scores on all items were averaged to create a reliable scale $(\alpha=.68)$. After that, all participants were fully debriefed, thanked, and received a movie-ticket for their participation.

Results

\section{Modern and Classical Sexism}

As expected, men $(M=3.15, S D=.75)$ scored higher on modern sexism than did women $(M=2.19, S D=.51), t(34)=4.49, p<.001$. In a similar vein, men $(M=2.33, S D=.59)$ scored higher on classical sexism than did women $(M=1.79, S D=.42), t(34)=3.13, p<.01$. Consistent with previous research

\footnotetext{
1 This study assessed procedural justice judgments in response to a scenario in which people either imagined receiving or not receiving voice before a resource allocation decision was made by an authority.
} 
(Ekehammar et al., 2000), we further note that modern and classical sexism scores were positively correlated $(r=.52, p=.001)$.

\section{Social Desirability Concerns}

No gender differences in social desirability concerns were found $(M=4.67$, $S D=.85), t(34)=-1.29, p=.21$. Furthermore, we found no reliable relationships between social desirability concerns and the MS scale $(r=-.16, p=.35)$, the CS scale $(r=-.11, p=.53)$, or rape victim blaming $(r=-.09, p=.60)$. Separate analyses for men and women indicated that social desirability concerns were unrelated to all three scales among male as well as female participants (all $p s>.18$ ). Thus, there is no evidence to suggest that our measures were significantly contaminated by self-presentation biases.

\section{Rape Victim Blaming}

Our main hypothesis that MS should primarily predict victim blaming among men (vs. women) was tested by means of hierarchical regression analyses. Victim blaming scores were regressed on sex of participant, modern sexism scores, and their interaction, while controlling for classical sexism scores. Following Cohen, Cohen, West, and Aiken (2003), we centered participants' answers on the MS and CS scales (by subtracting the mean from each individual score), and effect-coded participants' gender ( 1 for men and -1 for women) before creating the relevant interaction term. In Step 1 we entered the independent variables (Sex, MS, and CS) to examine possible main effects. The two-way interaction term $(\operatorname{Sex} \times \mathrm{MS})$ relevant for testing our hypothesis was entered in Step 2. The results are presented in Table 1.

Step 1 accounted for a significant part of the variance in rape victim blaming, $\Delta R^{2}=.21, F(3,32)=2.84, p=.05$. The main effect of MS was significant, whereas the main effects of participant sex and CS were not. More importantly, however, Step 2 also accounted for a marginally significant amount of variance in rape victim blaming, $\Delta R^{2}=.07, F(1,32)=3.08, p=.09$. The two-way interaction is depicted in Fig. 1. In support of our hypothesis, simple slope analyses confirmed that MS predicted victim blaming among men $(\beta=.59, p<.025)$, but not among women $(\beta=.02, p=.93)$, when differences in CS were statistically controlled for. By contrast, when controlling for MS, CS was unrelated to victim blaming among men $(\beta=-.10, p=.65)$ as well as among women $(\beta=-.26, p=.33)$.

Table 1 Results from hierarchical regression analyses: victim blaming as a function of sex, classical sexism, and modern sexism (Study 1)

Note: ${ }^{\dagger} p<.10 . * p<.05$

\begin{tabular}{lrcr}
\hline Regression step & $\beta$ & $t$ & $\Delta R^{2}$ \\
\hline Step 1 & & & \\
Sex of participant & .06 & .27 & \\
Classical sexism & -.17 & -.91 & \\
Modern sexism & .49 & $2.34^{*}$ & $.21^{*}$ \\
Step 2 & & & \\
Sex $\times$ MS & .29 & $1.76^{\dagger}$ & $.07^{\dagger}$ \\
\hline
\end{tabular}




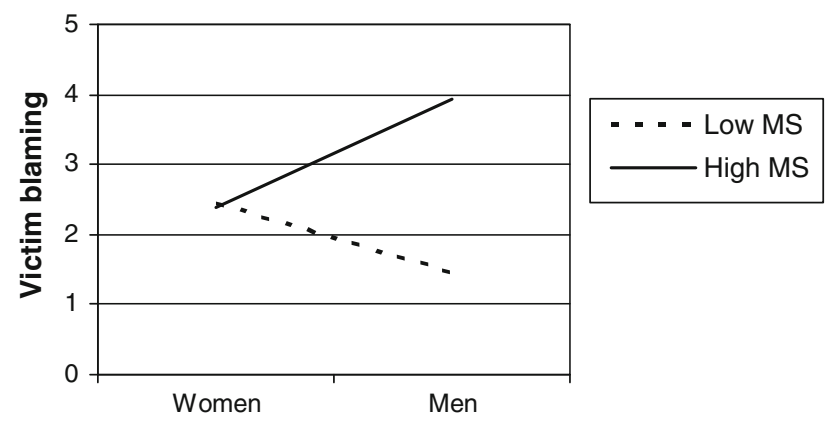

Fig. 1 Victim blaming as a function of sex and modern sexism (Study 1)

\section{Discussion}

The results of Study 1 confirmed that gender-related system justification motivation predicted the propensity to blame a victim of rape among men, but not among women. Notably, these results were obtained when differences in a general antipathy towards women were statistically controlled for. This corroborates our argument that modern sexism contributes to rape victim blaming because it taps into gender-related system justification motivation, and not because it taps into negative attitudes towards women (Lonsway \& Fitzgerald, 1995). However, it should be noted here that, although the analyses of simple slopes supported our hypothesis, the participant sex $\times$ MS interaction only reached marginal significance. Therefore, it is important to replicate these findings to confirm their reliability before strong conclusions are drawn.

System justification motivation was uncorrelated with women's propensity to blame a rape victim in this study. Thus, only members of the advantaged group (men) displayed system justifying responses. It could, therefore, be argued that these findings are at least as consistent with a group-serving account of victim-derogation (e.g., social dominance, Sidanius \& Pratto, 1999) as with system justification theory. After all, system justification theory holds that both members of advantaged and disadvantaged groups are motivated to defend the status quo, and should display system justifying responses. However, research also suggests that system justifying responses among members of disadvantaged groups are contingent on the activation of complementary stereotypes (Jost \& Kay, 2005). Thus, if the system justification account of our findings is correct, gender-related system justification motivation should predict victim blaming among women once complementary stereotypes have been activated. We tested this hypothesis in a second study.

\section{Study 2}

In Study 2 we compared how men and women with different levels of genderrelated system justification motivation (MS) reacted to a particular rape victim depending on whether complementary stereotypes about women had been primed. If 
our system justification interpretation were correct, we would expect MS to emerge as a potent predictor of victim blaming among women when complementary stereotypes about women have been primed. Moreover, to the extent that complementary stereotypes exert their influence by facilitating rationalizations of gender-based inequalities, we would expect complementary stereotypes to primarily affect women who score relatively high on system justifying motivation (i.e., high on MS). Among men, gender-related system justification motivation coincides with protection of group interests. We, therefore, expected MS to be an equally potent predictor of victim blaming among men irrespective of whether complementary stereotypes about women had been primed. We tested this hypothesis by priming complementary stereotypes about women (vs. control) and examined the consequences for victim blaming among men and women depending on their level of gender-related system justification motivation.

\section{Method}

\section{Participants}

Undergraduate students at University of Skövde ( $N=72,35$ men, 37 women) between 19 and $39(M=24, S D=4.03)$ years of age were randomly assigned either to the complementary stereotype activation condition or to the control condition. Participation took approximately $30 \mathrm{~min}$ and all participants received a movie-ticket in return for their participation.

\section{Materials and Procedure}

Materials were handed out during regular classes. A female experimenter monitored participants and informed them that their participation was guaranteed to be anonymous. Participants were instructed that the questionnaire contained two different studies. It was further stressed that materials should be filled out in the order presented in the questionnaire. The first part of the questionnaire was introduced as a grammatical test. In reality, the grammatical test was a scrambled sentence task used to prime complementary stereotypes about women (vs. control). Notably, scrambled sentence tasks have frequently been used to increase the accessibility of various knowledge structures, such as traits and stereotypes (Bargh \& Chartrand, 2000). Participants were presented with a total of 12 word strings, where each word string contained five words. They were informed that the task was to create a sentence out of each word string using four of the five words.

In the stereotype activation condition eight of the word strings contained a stereotypically female trait derived from previous research on gender stereotypes (Blair \& Banaji, 1996; Crawford, Leynes, Mayhorn, \& Bink, 2004), and four word strings contained only neutral words. The female traits used were: weak, hysterical, caring, manipulative, sensitive, powerless, emotional, and seductive. To illustrate, one of the word strings containing a word associated with a positive stereotypical characteristic of women was: "caring are us they people" (unscrambled: they are caring people). One of the word strings containing a word associated with a negative 
stereotypic characteristic of women was: "was music seductive can be" (unscrambled: music can be seductive). Consistent with previous research where scrambled sentence tasks were used to activate stereotypes, we expected that the mere exposure to stereotype-related trait words should increase the accessibility of the stereotype, even when the sentences constructed were unrelated to the stereotype (e.g., Bargh, Chen, \& Burrows, 1996). In the control condition, all 12 word strings contained only words theoretically unrelated to stereotypes about women. An example of a word string containing only neutral words was: "sparkles winter snow in the sun" (unscrambled: snow sparkles in the sun). ${ }^{2}$

After the scrambled sentence task, participants turned the page to find the same scenario as the one used in Study 1. After the scenario, victim blaming was measured on a 6 -point scale $(1=$ to a very low extent; $6=$ to a very high extent $)$, using the same three items as in Study $1(\alpha=.79)$. After the dependent variables we finally measured individual differences in modern sexism $(\alpha=.73)$, using the same MS scale as in Study 1. For conclusions about causality, it would have been preferable to measure MS at the outset of the study. For this study, however, we were concerned that this would interfere with our subtle stereotype activation manipulation. Moreover, the MS scale presumably taps relatively stable individual differences in modern sexist attitudes. Indeed, there is evidence that measures of contemporary forms of sexism have high test-retest reliability (Masser, 1998; Masser \& Abrams, 1999). We, therefore, decided to measure MS at the end of the study and to check for any differences in MS as a result of our experimental manipulation. After filling out the MS scale followed by an additional unrelated questionnaire, all participants were fully debriefed, thanked, and paid a movie-ticket for their participation.

Results

\section{Initial Analyses}

To check the stability of modern sexism scores we subjected the MS scale to a 2 (participant sex: male/female) $\times 2$ (prime: complementary stereotype/control) ANOVA. The only significant effect obtained was the expected main effect of participant sex, $F(1,68)=28.78, p<.001$. Men $(M=2.87 ; S D=.60)$ scored higher than women $(M=2.14 ; S D=.54)$ on the MS scale. Importantly, no effects involving the stereotype activation manipulation approached significance ( $p$ s $>.46$ ). We thus conclude that modern sexist attitudes were unaffected by our experimental manipulation, and hence could be used as a predictor variable in subsequent analyses.

\footnotetext{
${ }^{2}$ Six words were required to accurately translate the original Swedish word string into English. In the Swedish stimulus materials, however, the word string contained only five words (gnistrar vintern snön $\mathrm{i}$ solen). The unscrambled sentence only contained four words (snön gnistrar i solen). Also note that the words associated with stereotypes about women were italicized here, but not in the original stimulus materials.
} 


\section{Victim Blaming}

Victim blaming was analyzed by means of hierarchical regression analyses. In Step 1 we entered each independent variable (sex, prime, MS) to examine the main effects. The two-way interaction terms $($ sex $\times$ prime, sex $\times$ MS, prime $\times$ MS $)$ were entered in Step 2. In Step 3 we entered the three-way interaction term $(\operatorname{sex} \times$ prime $\times$ MS) relevant for testing our hypotheses. As in Study 1, we centered participants' answers on the MS scale, and effect-coded participant sex (1 for men and -1 for women) as well as the prime ( 1 for female stereotype and -1 for control) before creating the interaction terms. Results are presented in Table 2.

As can be seen in Table 2, Step 1 accounted for a significant part of the variance in victim blaming, $\Delta R^{2}=.30, F(3,68)=9.70, p<.001$. MS predicted victim blaming, as did participant sex, whereas stereotype activation did not. Step 2 did not explain any additional variance, $\Delta R^{2}=.03$, ns. More importantly, and in line with our hypothesis, Step 3 explained a significant amount of additional variance, $\Delta R^{2}=.05, F(1,64)=4.90, p<.05$.

To interpret the significant three-way interaction we first conducted separate analyses for the control condition and for the stereotype activation condition. Replicating findings from Study 1 , the participant sex $\times$ MS interaction term predicted victim blaming in the control condition $(\beta=.33, p<.05)$. Simple slope analyses confirmed that, in the control condition, MS predicted victim blaming among men $(\beta=.54, p<.025)$, but not among women $(\beta=-.18, p=.47)$. In the stereotype activation condition, however, only MS emerged as a significant predictor of victim blaming $(\beta=.49, p<.01)$. The sex $\times$ MS interaction did not approach significance in the stereotype activation condition $(\beta=-.13, p=.37)$.

We then conducted separate analyses for men and women. Results among men are depicted in Fig. 2. Among men, only MS predicted victim blaming $(\beta=.45$, $p<.01)$. Neither the prime nor the prime $\times$ MS interaction approached significance $(p s>.55)$. Thus, MS predicted men's victim blaming regardless of whether complementary stereotypes had been primed. Results among women are depicted in Fig. 3. Neither MS nor the prime predicted victim blaming among women $(p s>.16)$. However, a prime $\times$ MS interaction was found $(\beta=.50, p<.025)$.

Table 2 Results from hierarchical regression analyses: victim blaming as a function of sex, modern sexism, and stereotype activation (Study 2)

Note: ${ }^{\dagger} p<.10, * p<.05$. $* * p<.01, * * * p<.001$

\begin{tabular}{lrrr}
\hline Regression step & $\beta$ & \multicolumn{1}{l}{$t$} & $\Delta R^{2}$ \\
\hline Step 1 & & & \\
$\quad$ Sex of participant & .23 & $1.92^{\dagger}$ & \\
Modern Sexism & .38 & $3.14^{* *}$ & \\
Stereotype activation & .09 & .88 & $.30^{* * *}$ \\
Step 2 & & & \\
Sex $\times$ MS & .12 & 1.14 & \\
Sex $\times$ Stereotype activation & -.09 & -.72 & \\
MS $\times$ Stereotype activation & .15 & 1.21 & .03 \\
Step 3 & & & \\
Sex $\times$ MS $\times$ Stereotype activation & -.27 & $-2.21^{*}$ & $.05^{*}$ \\
\hline
\end{tabular}




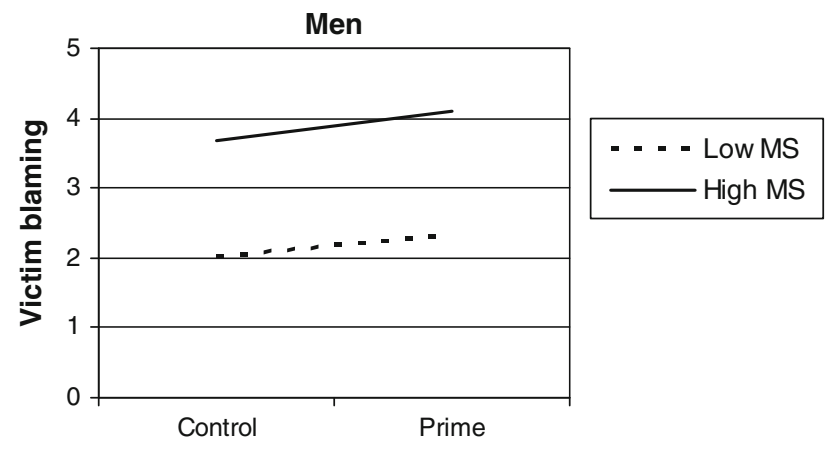

Fig. 2 Victim blaming among men as a function of stereotype activation and modern sexism (Study 2)

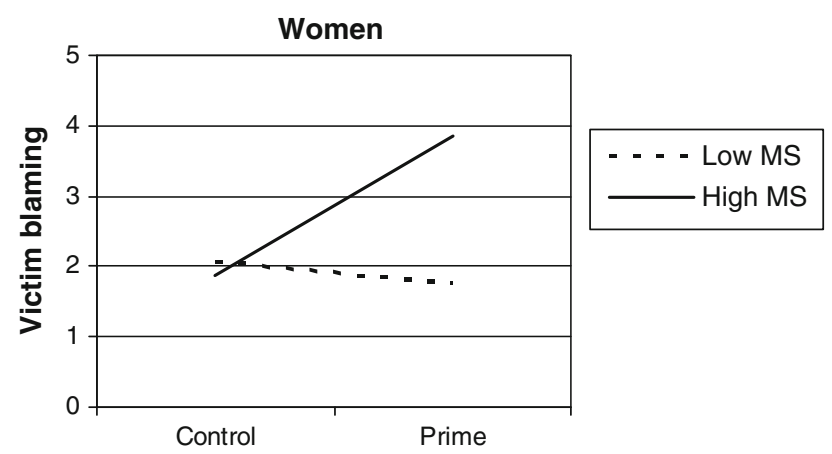

Fig. 3 Victim blaming among women as a function of stereotype activation and modern sexism (Study 2)

Simple slope analyses revealed that MS predicted victim blaming among women when complementary stereotypes about women had been primed $(\beta=.61$, $p<.01)$, but not in the control condition $(\beta=-.18, p=.47)$. Additional analyses further demonstrated that the prime affected victim blaming among women high on modern sexism $(\beta=.82, p<.025)$, but not among women low on modern sexism $(\beta=-.03, p=.87)$. Thus, when complementary stereotypes about women had been primed, MS emerged as a potent predictor of victim blaming among women. Moreover, activation of complementary stereotypes about women only affected victim blaming among women who endorsed modern sexist attitudes. Taken together, these findings support a system justification account of rape victim blaming.

\section{Discussion}

The findings of Study 2 further corroborated the idea that gender-related system justification motivation predicts men's propensity to blame a female rape victim. Importantly, results from the control condition replicated the results of Study 
1 - and this time the sex $\times$ MS interaction reached conventional levels of statistical significance, suggesting that this finding is indeed reliable. As in Study 1, women's propensity to blame a female rape victim was unrelated to modern sexist attitudes by default. However, consistent with system justification theory, this study demonstrated that there are situations in which modern sexist attitudes do predict victim blaming among women. Specifically, modern sexist attitudes emerged as a predictor of victim blaming among women when complementary stereotypes about women had been primed. The fact that modern sexist attitudes can predict victim blaming among members of the advantaged as well as the disadvantaged group supports the notion that rape victim blaming serves a system justifying function, and speaks against group justification accounts of victim blaming. In further support of this interpretation, activating complementary stereotypes about women only affected victim blaming among women who endorsed modern sexist attitudes.

By contrast, men's propensity to blame the victim was unaffected by the activation of complementary stereotypes about women. This is not surprising, as rape victim blaming can serve several functions among men. Not only does it serve to justify the system, but also to protect (real or symbolic) interests of their group. As a result, men who endorse modern sexist attitudes may not need complementary stereotypes in order to assign blame to a female rape victim. To conclude, this study demonstrated that complementary stereotypes, once activated, have the potential to trigger system justifying responses to rape victims among women.

\section{General Discussion}

This research was initiated to examine a motivational account of rape victim blaming beyond that provided by a general antipathy towards women (Lonsway \& Fitzgerald, 1995). Specifically, we attempted to advance the understanding of negative responses to rape victims by connecting such reactions to system justification motivation. The first aim of this research was to examine whether system justification motivation predicted reactions to a female rape victim when variance explained by a general antipathy towards women was statistically controlled for, and when social desirability concerns were taken into account. Despite the sensitive nature of the research topic, data from Study 1 suggested that social desirability concerns had little influence on our measures. Furthermore, as expected, results of Study 1 revealed that men high (vs. low) on gender-related system justification were more inclined to blame a victim of a depicted rape and that this finding was not attributable to a general antipathy towards women. Among women, system justification motivation was unrelated to victim blaming. While these findings provided initial support for our line of reasoning, it should be noted that the participant sex $\times$ MS interaction only reached marginal significance. It was, therefore, important to replicate these findings before any strong conclusions were drawn.

Aside from attempting to replicate results from Study 1, the main aim of Study 2 was to find more conclusive evidence for the system justification account of the relationship between modern sexist attitudes and responses to rape victims. We have 
argued that the MS scale predicts rape victim blaming among men because it taps into individual differences in gender-related system justification motivation. If this explanation were correct, the MS scale should predict victim blaming also among women under certain circumstances. Specifically, previous research on genderrelated system justification has demonstrated that women can display equally strong support for the system as men, provided that complementary stereotypes have been activated (Jost \& Kay, 2005). Therefore, to the extent that victim blaming is driven by system justification motives, we argued that MS should predict victim blaming among women when complementary stereotypes have been activated. Once activated, complementary stereotypes should reduce the salience of group-based concerns and thereby facilitate rationalizations of a negative response towards the victim among women high on system justification motivation. Results indeed revealed that MS and activation of complementary stereotypes interactively determined women's responses to the victim. Supporting the system justification interpretation, MS predicted rape victim blaming among women when complementary stereotypes about women had been primed, but not in the control condition. Furthermore, priming complementary stereotypes only affected victim blaming among women who had relatively strong (vs. weak) system justifying motives (i.e., women high on MS). By contrast, MS predicted men's responses to the victim irrespective of whether complementary stereotypes had been primed.

\section{Conclusions, Limitations, and Suggestions for Future Research}

As discussed above, results of the two studies strongly suggest that system justification motivation indeed contributes to rape victim blaming. At the same time, however, this research is not without its limitations. First and foremost, we consistently operationalized system justification motivation in terms of modern sexist attitudes. As the MS scale measures denial of gender discrimination and opposition to social changes aiming to improve the position of women (Ekehammar et al., 2000; Swim et al., 1995), the scale was highly appropriate to capture genderrelated system justification motivation (e.g., Jost \& Hunyady, 2005). Furthermore, the fact that we consistently used the same measure of system justification ensured comparability across studies, and speaks to the reliability of the associations examined. On the other hand, this approach also raises concerns about generalizability. System justification is ultimately a broad concept that has been operationalized in various ways, including protestant work ethic (Jost \& Hunyady, 2002), belief in a just world (Jost \& Burgess, 2000), meritocratic ideology (Jost et al., 2003), and power distance (Jost et al., 2003). As we consistently assessed system justification in terms of modern sexist attitudes, one may wonder whether it was a general system justification motive that contributed to the effects obtained or something specific about modern sexism. In response to this, we think it is important to note that we did not solely demonstrate a relationship between modern sexist attitudes and victim blaming. In Study 2, we were also able to experimentally moderate the relationship between modern sexist attitudes and victim blaming. We did so by manipulating a variable (complementary stereotypes) previously shown to moderate system justifying responses. Furthermore, consistent with previous 
research, complementary stereotypes facilitated gender-related system justifying responses exclusively among women (Kay \& Jost, 2003). We think the fact that we were able to predict such a complex pattern of results on the basis of system justification theory, as well as the fact that this effect is consistent with previous research provides compelling support for a system justification account of our findings and speaks against alternative interpretations.

It is also interesting to note that there is some indirect support for a system justification explanation of rape victim blaming from a study in which a different measure of system justification was used. Kleinke and Meyer (1990) found that individual differences in the belief in a just world predicted rape victim blaming. Furthermore, and consistent with the findings of the present studies, system justification motives (BJW) only had a positive relationship with victim blaming among men, and not among women. Thus, it seems that system justification motivation, irrespective of whether it is operationalized as modern sexist attitudes or as just world beliefs, primarily predicts rape victim blaming among men-provided that complementary stereotypes have not been activated. That said, however, we encourage additional research aimed to test the generalizability of our findings. Furthermore, we also recognize the need for studies that enable more conservative tests of causality. For example, we assessed differences in modern sexism after the manipulation of complementary stereotypes (Study 2). This was done to prevent exposure to the modern sexism items from interfering with our subtle priming manipulation. Notably, our modern sexism measure was unaffected by the complementary stereotype primes, suggesting that this scale taps into relatively stable individual differences. However, it seems worthwhile to conduct additional studies in which men and women high versus low on modern sexism (or another measure of system justification motivation) are pre-selected to participate in a similar complementary stereotype priming experiment. In addition, future studies could attempt to manipulate rather than measure system justification motivation, for example, by inducing system threat or mortality salience (cf. Jost et al., 2003; Landau et al., 2004) and examine its consequences for men and women's reactions to rape victims. Such studies could provide conclusive evidence of the causal relationships proposed by system justification theory.

In concluding we return to the question that instigated this research. In two studies we have demonstrated that modern sexist attitudes generally contribute to attributions of blame to a rape victim among men (but not among women). Consistent with a system justification account of these findings, once complementary stereotypes about women have been activated, modern sexist attitudes contribute to victim blaming also among women. We thus conclude that modern sexist attitudes and the activation of complementary stereotypes about women are important antecedents of rape victim blaming. This suggests that rape victim blaming can be understood in part as an attempt to justify contemporary genderbased inequalities.

Acknowledgments The research reported in this article was supported by a research grant from School of Technology and Society, University of Skövde, awarded to the first and second authors. We thank Patrik Ekwall, Anna Fahgén, Shaho Ghanbari, Ibrahim Kaymak, and Malin Thörnberg for their assistance 
in collecting the data. We are also grateful to John Jost and four anonymous reviewers for valuable comments on a previous version of this article.

Open Access This article is distributed under the terms of the Creative Commons Attribution Noncommercial License which permits any noncommercial use, distribution, and reproduction in any medium, provided the original author(s) and source are credited.

\section{Appendix}

\section{Scenario}

It is a Friday night, and eighteen-year-old Sara is at a private party together with her friends and some other people that she does not know. Sara is dressed in a tight top and a short skirt. The evening proceeds and everyone is having a very good time. Sara is dancing with Mikael, a boy she has met at other parties, but does not really know that well. Sara's friends eventually decide to leave the party and they ask her whether she will join them. As she's having such a good time dancing, Sara tells them that she will stay a bit longer.

Later on Sara is feeling tired and a bit dizzy from the alcohol she's had and Mikael shows her to a room where she can lie down and rest. Mikael lies down next to her on the bed and starts talking, but Sara does not really listen. Mikael then starts touching her and Sara tells him to leave her alone. Mikael ignores this and instead proceeds by taking of Sara's skirt. Sara repeatedly tells him to leave her alone, but Mikael continues to ignore her. He takes of his own clothes and has sexual intercourse with Sara.

In the morning Sara thinks through everything that happened during the night and then goes to the police to report that she has been raped.

\section{References}

Abrams, D., Viki, T., Masser, B., \& Bohner, G. (2003). Perceptions of stranger and acquaintance rape: The role of benevolent and hostile sexism in victim blame and rape proclivity. Journal of Personality and Social Psychology, 84, 111-125.

Bargh, J. A., \& Chartrand, T. L. (2000). The mind in the middle: A practical guide to priming and automaticity research. In H. T. Reis \& M. Judd (Eds.), Handbook of research methods in social and personality psychology (pp. 253-285). New York: Cambridge University Press.

Bargh, J. A., Chen, M., \& Burrows, L. (1996). Automaticity of social behavior: Direct effects of trait construct and stereotype activation on action. Journal of Personality and Social Psychology, 71, 230-244.

Blair, I. V., \& Banaji, M. R. (1996). Automatic and controlled processes in stereotype priming. Journal of Personality and Social Psychology, 70, 1142-1163.

Blumberg, M. L., \& Lester, D. (1991). High school and college students' attitudes toward rape. Adolescence, 26, 727-729.

Bohner, G., Siebler, F., \& Raaijmakers, Y. (1999). Salience of rape affects self-esteem: Individual versus collective self-aspects. Group Processes and Intergroup Relations, 2, 191-199. 
BRÅ. (2005). Vaildtäkt: En kartläggning av polisanmälda vaildtäkter [Rape: A mapping of rape incidents reported to the police]. BRÄ-rapport 2005: 7. Stockholm: Brottsförebyggande rådet. Fritzes.

Burt, M. R. (1980). Cultural myths and supports for rape. Journal of Personality and Social Psychology, $38,217-230$.

Campbell, R., Sefl, T., Barnes, H. E., Ahrens, C. E., Wasco, S. M., \& Zaracgoza-Diesfeld, Y. (1999). Community services for rape survivors: Enhancing psychological well-being or increasing trauma? Journal of Consulting and Clinical Psychology, 67, 847-858.

Check, J. V. P., \& Malamuth, N. M. (1985). An empirical assessment of some feminist hypotheses about rape. International Journal of Women's Studies, 8, 414-423.

Cohen, J., Cohen, P., West, S. G., \& Aiken, L. S. (2003). Applied multiple regression/correlation analysis for the behavioral sciences (3rd ed.). Mahwah, NJ: Lawrence Erlbaum Associates.

Correia, I., Vala, J., \& Aguiar, P. (2007). Victim's innocence, social categorization, and the threat to the belief in a just world. Journal of Experimental Social Psychology, 43, 31-38.

Crawford, J. T., Leynes, P. A., Mayhorn, C. B., \& Bink, M. L. (2004). Champagne, beer, or coffee? A corpus of gender-related and neutral words. Behavior Research Methods, Instruments, and Computers, 36, 444-458.

Crowne, D. P., \& Marlowe, D. (1960). A new scale of social desirability independent of psychopathology. Journal of Consulting Psychology, 24, 349-354.

Ekehammar, B., Akrami, N., \& Araya, T. (2000). Development and validation of Swedish classical and modern sexism scales. Scandinavian Journal of Psychology, 41, 307-314.

Fischer, G. J. (1986). College student attitudes toward forcible date rape: 1. Cognitive predictors. Archives of Sexual Behavior, 15, 457-466.

Gerger, H., Kley, H., Bohner, G., \& Siebler, F. (2007). The acceptance of modern myths about sexual aggression scale: Development and validation in German and English. Aggressive Behavior, 33, $422-440$.

Hafer, C. L. (2000). Do victims threaten the belief in a just world? Evidence from a modified Stroop task. Journal of Personality and Social Psychology, 79, 165-173.

Jenkins, M. J., \& Dambrot, F. H. (1987). The attribution of date rape: Observer's attitudes and sexual experiences and the dating situation. Journal of Applied Social Psychology, 17, 875-895.

Jost, J. T., \& Banaji, M. R. (1994). The role of stereotyping in system-justification and the production of false consciousness. British Journal of Social Psychology, 33, 1-27.

Jost, J. T., Banaji, M. R., \& Nosek, B. A. (2004). A decade of system justification theory: Accumulated evidence of conscious and unconscious bolstering of the status quo. Political Psychology, 25, 881-919.

Jost, J. T., Blount, S., Pfeffer, J., \& Hunyady, G. (2003a). Fair market ideology: Its cognitive-motivational underpinnings. In B. M. Staw \& R. M. Kramer (Eds.), Research in organizational behavior: An annual series of analytical essays and critical reviews, Vol 25**** (pp. 53-91). Oxford, England: Elsevier Science Ltd.

Jost, J. T., \& Burgess, D. (2000). Attitudinal ambivalence and the conflict between group and system justification motives in low status groups. Personality and Social Psychology Bulletin, 26, 293-305.

Jost, J. T., Glaser, J., Kruglanski, A. W., \& Sulloway, F. (2003b). Political conservatism as motivated social cognition. Psychological Bulletin, 129, 339-375.

Jost, J. T., \& Hunyady, O. (2002). The psychology of system justification and the palliative function of ideology. European Review of Social Psychology, 13, 111-153.

Jost, J. T., \& Hunyady, O. (2005). Antecedents and consequences of system-justifying ideologies. Current Directions in Psychological Science, 14, 260-265.

Jost, J. T., \& Kay, A. C. (2005). Exposure to benevolent sexism and complementary gender stereotypes: Consequences for specific and diffuse forms of system justification. Journal of Personality and Social Psychology, 88, 498-509.

Jost, J. T., Pelham, B. W., Sheldon, O., \& Sullivan, B. N. (2003c). Social inequality and the reduction of ideological dissonance on behalf of the system: Evidence of enhanced system justification among the disadvantaged. European Journal of Social Psychology, 33, 13-36.

Jost, J. T., \& Thompson, E. P. (2000). Group-based dominance and opposition to equality as independent predictors of self-esteem, ethnocentrism, and social policy attitudes among African Americans and European Americans. Journal of Experimental Social Psychology, 36, 209-232.

Katz, B. L., \& Burt, M. R. (1988). Self-blame in recovery from rape: Help or hindrance? In A. W. Burgess (Ed.), Rape and sexual assault II (pp. 151-168). New York: Garland. 
Kay, A. C., \& Jost, J. T. (2003). Complementary justice: Effects of "poor but happy" and "poor but honest" stereotype exemplars on system justification and implicit activation of the justice motive. Journal of Personality and Social Psychology, 85, 823-837.

Kay, A. C., Jost, J. T., \& Young, S. (2005). Victim derogation and victim enhancement as alternate routes to system justification. Psychological Science, 16, 240-246.

Kleinke, C. L., \& Meyer, C. (1990). Evaluation of rape victim by men and women with high and low belief in a just world. Psychology of Women Quarterly, 14, 343-353.

Landau, M. J., Solomon, S., Greenberg, J., Cohen, F., Pyszczynski, T., Arndt, J., et al. (2004). Deliver us from evil: The effects of mortality salience and reminders of 9/11 on support for President George W. Bush. Personality and Social Psychology Bulletin, 30, 1136-1150.

Lerner, M. J. (1980). The belief in a just world: A fundamental delusion. New York: Plenum.

Linz, D. G., Donnerstein, E., \& Adams, S. M. (1989). Physiological desensitization and judgments about female victims of violence. Human Communication Research, 15, 509-522.

Linz, D. G., Donnerstein, E., \& Penrod, S. (1988). Effects of long-term exposure to violent and sexually degrading depictions of women. Journal of Personality and Social Psychology, 5, 758-768.

Lonsway, K. A., \& Fitzgerald, L. F. (1994). Rape myths: In review. Psychology of Women Quarterly, 18, $133-164$.

Lonsway, K. A., \& Fitzgerald, L. F. (1995). Attitudinal antecedents of rape myth acceptance: A theoretical and empirical reexamination. Journal of Personality and Social Psychology, 68, $704-711$.

Masser, B. M. (1998). The ambivalent sexism inventory: A social psychological evaluation. Canterbury, England: Unpublished doctoral dissertation, University of Kent.

Masser, B. M., \& Abrams, D. (1999). Contemporary sexism: The relationships among hostility, benevolence and neosexism. Psychology of Women Quarterly, 23, 503-517.

Mogg, K., Mathews, A., Bird, C., \& Macgregor-Morris, R. (1990). Effects of stress and anxiety on the processing of threat stimuli. Journal of Personality and Social Psychology, 59, 1230-1237.

Muehlenhard, C. L., \& MacNaughton, J. S. (1988). Women's beliefs about women who "lead men on". Journal of Social and Clinical Psychology, 7, 65-79.

Norris, J., \& Cubbins, L. A. (1992). Dating, drinking, and rape: Effects of victim's and assailant's alcohol consumption on judgments of their behavior and traits. Psychology of Women Quarterly, 16, 179-191.

Pollard, P. (1992). Judgements about victims and attackers in depicted rapes: A review. British Journal of Social Psychology, 31, 307-326.

Quackenbush, R. L. (1989). A comparison of androgynous, masculine, sex-typed, and undifferentiated males on dimensions of attitudes toward rape. Journal of Research in Personality, 23, 318-342.

Sidanius, J., \& Pratto, F. (1999). Social dominance: An intergroup theory of social hierarchy and oppression. New York: Cambridge University Press.

Swim, J. K., Aikin, K. J., Hall, W. S., \& Hunter, B. A. (1995). Sexism and racism: Old-fashioned and modern prejudice. Journal of Personality and Social Psychology, 68, 199-214.

Williams, J. M. G., Mathews, A., \& MacLeod, C. (1996). The emotional Stroop task and psychopathology. Psychological Bulletin, 120, 3-24. 